ИЗВЕСТИЯ АКАДЕМИИ НАУК ЭСТОНСКОЯ ССР. ТОМ 31

ГЕОЛОГИЯ. 1982, Nㅗ 1

удК $56.016 .3: 551.73(474.2)$

К. ХАЗАНОВИЧ, В. МНССАРЖЕВСКИИ

\title{
ВОПРОСЫ СТРАТИГРАФИИ И ХИОЛИТЕЛЬМИНТЫ ЮЛГАЗЕСКИХ ОТЛОЖЕНИЙ ЭСТОНИИ
}

В процессе доразведки Мзардуского месторождения фосфоритов Управлением геологии ЭССР в 1976 и 1977 гг. было пробурено 25 скважин, вскрывших полный разрез оболовых песчаников пакерортского горизонта, включая самую нижнюю их часть - юлгазескую пачку. В результате изучения ее строения по керну скважин наряду с много численными находками беззамковых брахиопод были обнаружены ранее неизвестные из этой части разреза Восточно-Европейской платформы остатки представителей отряда Hyolithelminthes.

Возраст рассматриваемых отложений до настоящего времени трактовался как: 1) позднекембрийский - в результате анализа состава беззамковых брахиопод (Öpik, 1930) и геолого-литологических корреляций с предположительно позднекембрийскими образованиями (пестовской свитой) Московской синеклизы (Хазанович, 1969); 2) раннетремадокский - на основании изучения акритарх (Умнова, Фандерфлит, 1971; Янкаускас, Пашкявичене, 1972) и беззамковых брахиопод (Рымусокс и др., 1975).

В последние годы были получены новые данные, позволяющие рассматривать отложения юлгазеской пачки как дотремадокские. Во-первых, палеонтологически был доказан позднекембрийский возраст ладожской свиты на р. Ижоре Ленинградской области (Боровко и др., 1980), с которой юлгазеская пачка коррелируется по литолого-фациальной и микрофитологической характеристике (Плисов и др., 1977; Янкаускас, 1973). Во-вторых, юлгазеская пачка достаточно уверенно сопоставляется с петсерискими слоями на юго-востоке Эстонии, позднекембрийский возраст которых с учетом новых данных по акритархам достоверного верхнего кембрия Англии доказывается Н. А. Волковой (Волкова и др., 1981).

В настоящей статье мы не ставим задачей более подробное рассмотрение вопросов стратиграфии юлгазеской пачки, а обращаем внимание на их дискуссионность в связи с описанием новых палеонтологических остатков. Сохраняя традиции стратиграфических схем Эстонии, мы рассматриваем возраст юлгазеской пачки как условно раннеордовикский.

По результатам изучения керна буровых скважин в составе описываемой части разреза можно четко выделить две литологически различные пачки - нижнюю и верхнюю. Это обстоятельство вызывает необходимость укрупнения стратиграфического ранга юлгазеской пачки до свиты. В связи с этим, при дальнейшем изложении мы будем пользоваться термином юлгазеская свита. Переходим к описанию ее пачек.

Нижняя пачка сложена светло-серыми слабосцементированными неслоистыми преимущественно мелкозернистыми глинистыми алевролитами, содержащими редкий микроскопический детрит фосфатных раковин оболид. В нижней части пачки присутствуют характерные один или 


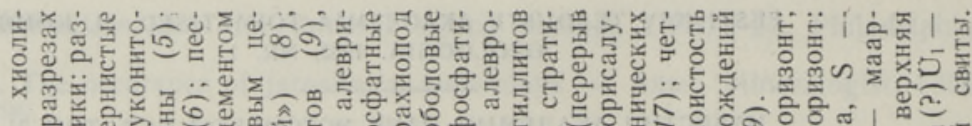

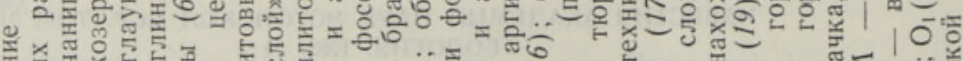

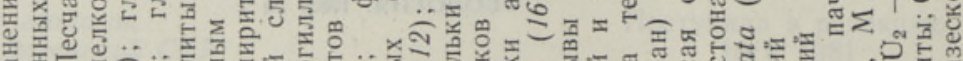

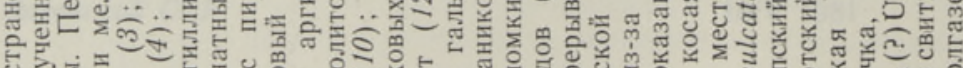

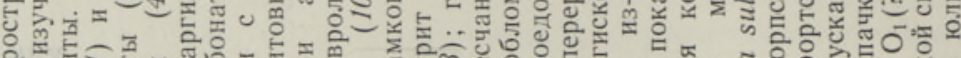
을 叫挐

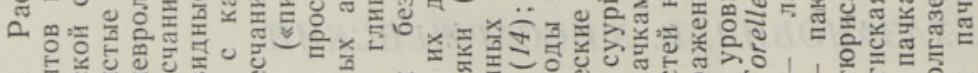

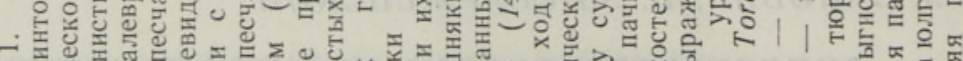

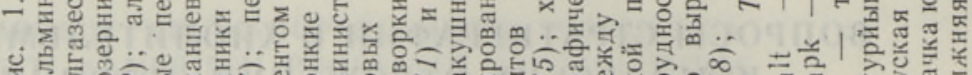

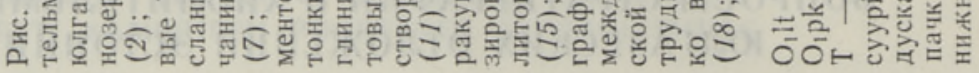
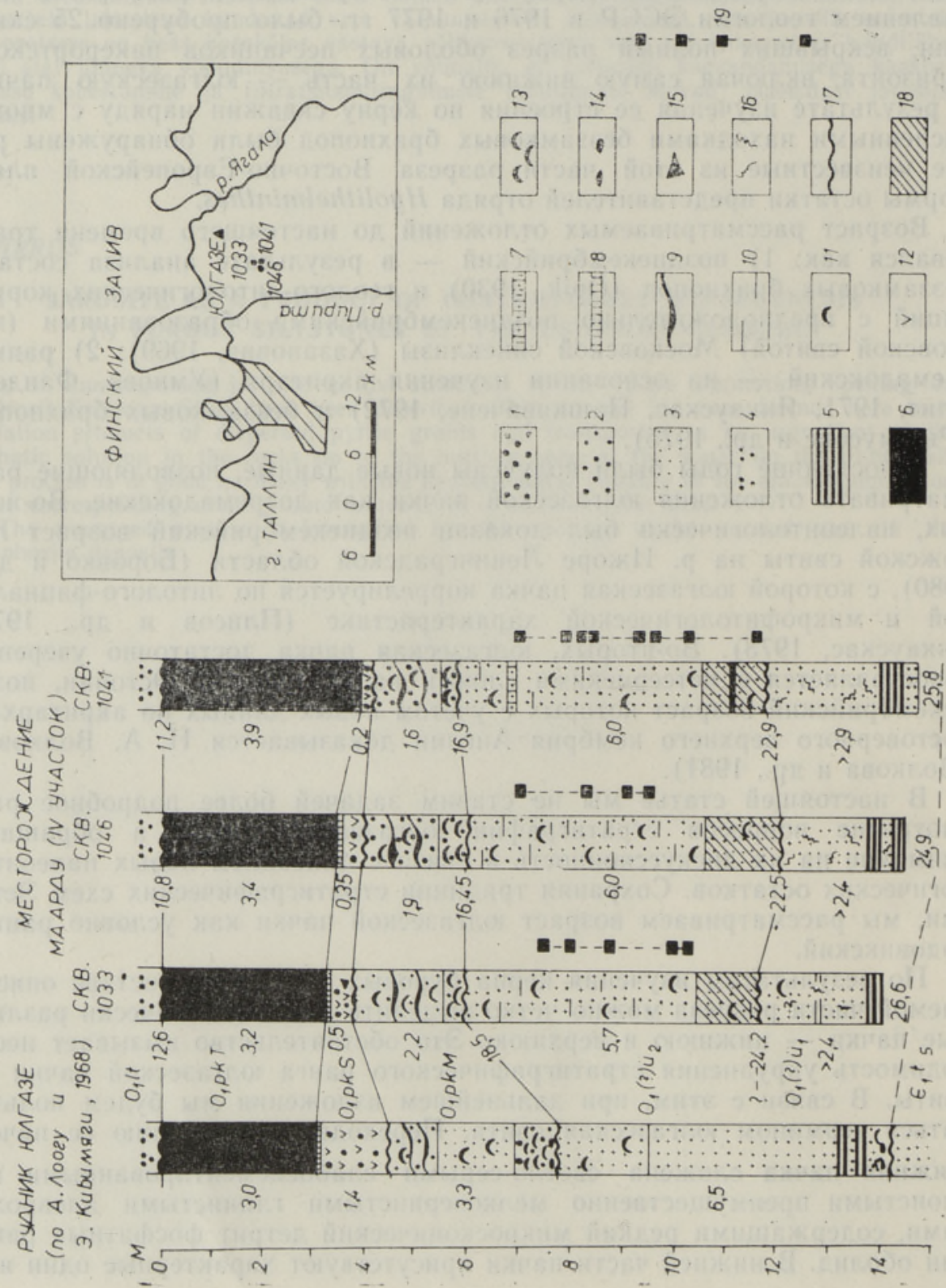


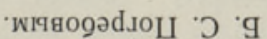

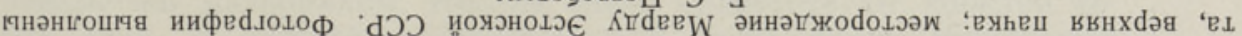

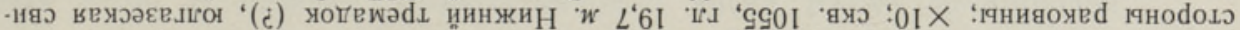

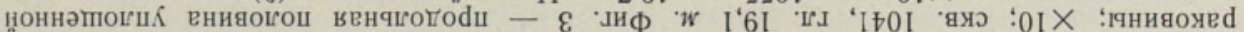

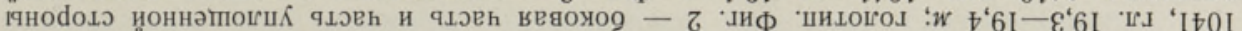
'яяว ؛ 0 X

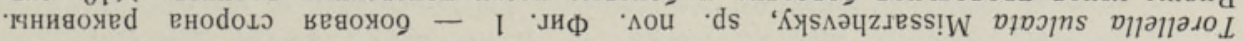
' $\mathcal{\varepsilon} \cdot \mathrm{\jmath н} \Phi$
乙 ЈиФ
· І '

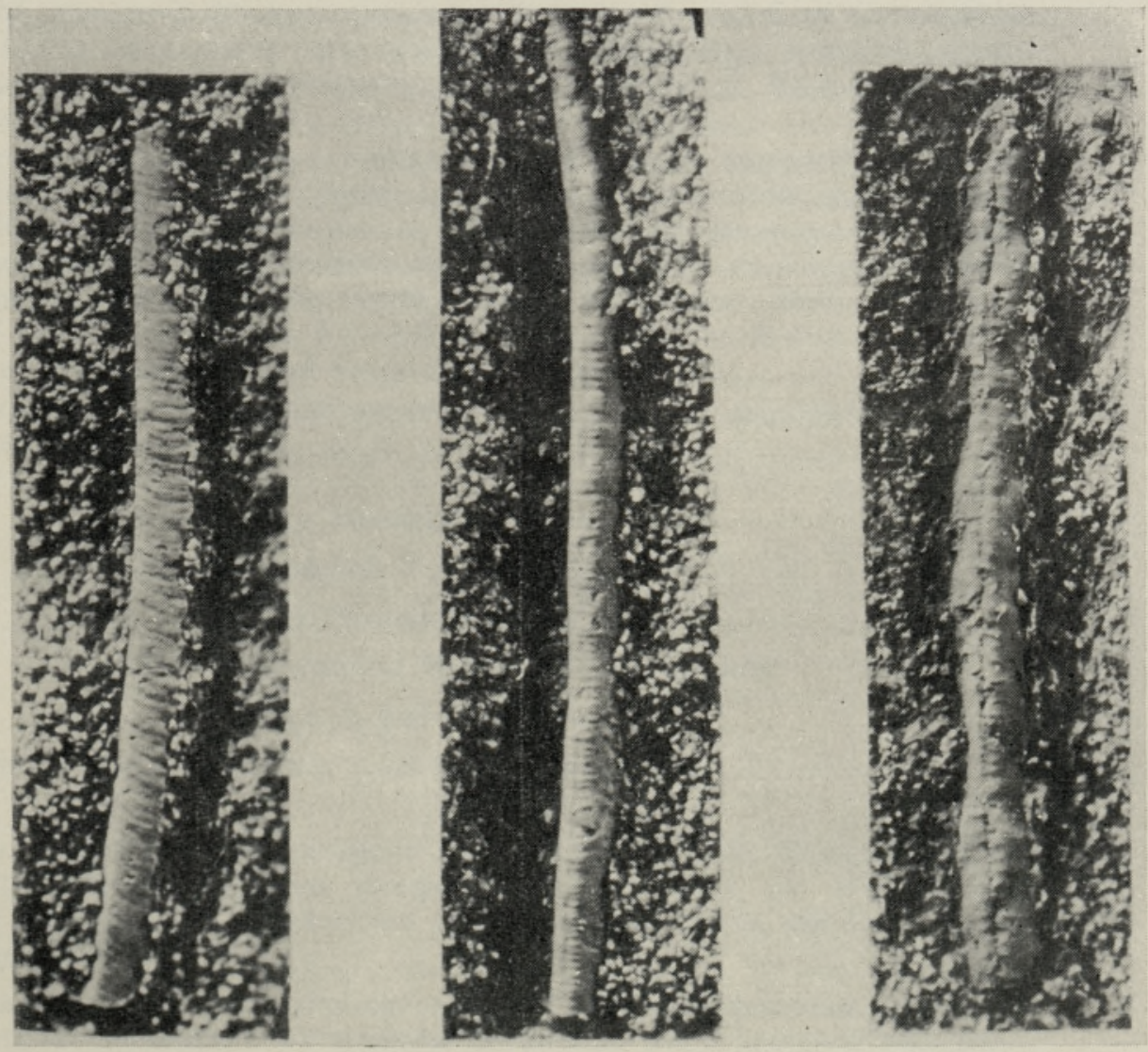

\section{ทПИน์}



два прослоя зеленых пластичных глин мощностью от 10 до $40 \mathrm{~cm}$. По всему разрезу в алевролитах отмечаются субвертикальные извилистые ходы илоедов диаметром $2-4$ мм и длиной до 3 см, выполненные зеленовато-серым, иногда слабо ожелезненным алеврито-глинистым материалом. Присутствуют мелкие тонкостенные раковины рода Schmidtites (?) хорошей coхранности. Вскрытая мощность пачки $2,4-3,0$ м. Судя по строению стратотипического разреза юлгазеской свиты (рис. 1), полная мощность пачки не должна превышать $3,1-3,2 \mathrm{M}$.

Верхняя пачка сложена крупнозернистым светло-серым алевролитом, содержащим на разных уровнях маломощные (до 0,5 cм) прослои алевролитов, обогащенных темно-серым, бурым, реже зеленоватосерым глинистым материалом. Иногда здесь присутствуют прослои зеленоватых глин. В нижней, приконтактовой части пачки мощностью $1,0-1,7$ м в алевролитах наблюдается четко выраженная косая слоистость, намечаемая чередованием нитевидных прослоев светло-серых крупных алевролитов и темно-серых глинистых разновидностей. В породах встречаются зерна глауконита, а также редкие тонкие (менее 1 мм) слойки, обогащенные мелким детритом тонкостенных раковин оболид. По всему разрезу пачки присутствуют хорошей сохранности створки беззамковых брахиопод родов Schmidtites (?) и Obolus. Kроме них в алевролитах часто встречаются обломки хиолительминтов рода Torellella, описание которых приводится ниже. В одной из скважин на высоте 0,2 м от верхней границы свиты установлены многочисленные объемные фрагменты граптолитов, по заключению Д. Кальо принадлежащие к роду Dictyonema.

Контакт верхней пачки с нижней резкий и четко выражен благодаря различиям в цвете, текстурных признаках и крупности зерен алевролитов. Контакт верхней пачки с вышележащей маардуской резкий, слегка неровный, с приуроченными к нему редкими гальками фосфатизированного песчаника (см. также Лоог, Кивимяги, 1968). Мощность верхней пачки составляет $5,7-6,5 м$, всей свиты - 8-10 м, с увеличением ее в сторону южной границы месторождения.

Переходим к палеонтологической части статьи, выполненной В. В. Миссаржевским.

\section{Отряд Hyolithelminthes Fisher \\ Семейство Torellellidae Hclm \\ Род Torellella Holm, 1893}

Torellella sulcata Missarzhevsky, sp. nov.

Табл. I, фиг. 1 -3; рис. 2,3

Название вида от sulcata (лат.) - бороздчатая.

Голотип. Геологический институт АН СССР, № 4298, Эстонская ССР, Маардуское месторождение фосфоритов, скв. 1041, гл. 19,3-19,4 м, нижний тремадок (?), юлгазеская свита, верхняя пачка; сборы К. К. Хазановича, 1976 г.

Материал. В коллекции имеется около 20 обломков раковин и несколько десятков образцов с их мелким детритом. Все раковины обломаны вдоль продольной оси по месту наименьшей толщины.

Описание. Саблевидно изогнутые в начальной части и почти прямые в устьевой, равномерно расширяющиеся килеватые раковины с линзовидным поперечным сечением. Наружная поверхность с поперечными 
Рис. 2. Поперечное сечение половины раковины Torellella sulcata.

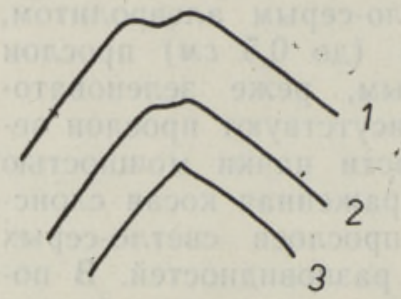

Рис. 3. Строение боковых сторон раковин различных видов рода Torellella: 1, 2 - T. sulcata sp. nov., $3-$ T. biconvexa Miss., T. lentiformis (Syss.).

валиками, выгнутыми в сторону устья. Валики каждой из сторон раковин соединяются друг с другом разделяющими стороны более или менее ярко выраженными боковыми продольными бороздками или продольно уплощенными участками. Вблизи борозд валики обычно несколько шире и выше, чем на остальной поверхности раковины. Внутренняя поверхность раковин гладкая. Многослойные стенки раковин неравномерной толщины. У боковых краев они макоимально толстые и постепенно утончаются к середине каждой из сторон. Утолщение достигается как за счет увеличения количества слоев раковин, так и за счет увеличения толщины каждого слоя. Наблюдавшиеся обломки раковин достигают максимальной длины 11 мм при длине сечения до 1 мм и ширине сечения до 0,4-0,7 мм. Количество валиков на 1 м. до 22 -23. Толщина стенок по осевой части сторон 0,05 мм, по бокам раковины до 0,2 ми.

Сравнение. От всех известных видов рода Torellella описываемый вид отличается прежде всего наличием продольных бороздок на боковых краях раковины, а также значительным утолшением стенок к боковым краям. Кроме того, можно отметить четко выраженное развитие валиков на наружной поверхности с характерным утолщением боковых бороздок. Наиболее близким видом можно назвать $T$. biconvexa Miss. из верхов томмотского яруса Сибирской платформы (Розанов и др., 1969). У них наблюдается сходство в форме и размерах раковины, но у последнего нет боковых бороздок, отсутствуют поперечные валики, а к боковым частям стенки утолщаются несравнимо меньше.

Замечания. Интересно отметить, что у раннекембрийских видов отсутствуют боковые бороздки. Этот элемент строения раковины, но выраженный не так четко, как у описываемых форм, пока обнаружен лишь у Torellella sp. из низов среднего кембрия Кузнецкого Алатау (Батеневский кряж, г. Сладкие Коренья). В этой связи можно предположить, что эволюция в морфологии тореллелл проявляется в закладке и развитии боковых бороздок, в увеличении толщины боковых стенок.

В юлгазеских слоях А. Эпиком были отмечены Hyolithus sp. (Öpik, 1930). Весьма вероятно, что этим названием были обозначены остатки описанного выше вида.

Распространение. Нижний тремадок (?) северо-запада ВосточноЕвропейской платформы.

Местонахождение. Верхняя пачка юлгазеской свиты Маардуского месторождения фосфоритов под Таллином, Әстонская ССР. 
Боровко Н. Г., Попов Л. Е., Сергеева С. П., Хазанович К. К. Новый комплекс палеонтологических остатков из нижней части оболовых песчаников на р. Ижоре. - Докл. АН СССР, 1980, 254, 1192-1194.

Волкова Н., Каяк К., Менс К., Пиррус Э. Новые данные о переходных слоях между кембрием и ордовиком на востоке Прибалтики. - Изв. АН ЭССР. Геол., 1981, 30, 51-55.

Л о о г А., К и в и м я г Э Э. Литостратиграфия пакерортского горизонта в Эстонии.Изв. АН ЭССР. Хим. Геол., 1968, 17, 374-385.

Плисов А. А., Го рян ски й В. Ю., Фандер флит Е. К. Новые данные о гра. нице кембрия и ордовика на северо-западе Русской плиты. - В кн.: Геологические позицин северо-западной окраины Русской плиты в свете новых гео-

лого-структурных данных. М., 1977, 3-13.
Р з а нов А. Ю., М и с сар жев ски й В. В., В олков а Н. А. и др. Томмотский ярус и проблема нижней границы кембрия. - Тр. Геол. ин-та АН СССР.
М., 1969, вып. 206 .

Ры мусокс А. К., Л оог А. Р., Кив и м г и Э. К. О геологин и фауне юлгазеской пачки. - Уч. зап. Тартуского ун-та. Тр. по геол., 1975, вып. 59, 3-13.

у м нова Н. И., Фандерф лит Е. К. Комплексы акритарх кембрийских и нижнеордовикских отложеннй запада и северо-запада Русской платформы. - В кн.: Палеонтологические исследования в Белоруссии и других районах СССР.
Минск, 1971, 45-73.

$\mathrm{X}$ аз ан ович К. К. Стратиграфня и условия формирования пограничных отложений кембрия и ордовика Ленинградской области и прилегающих районов. Автореф. канд. дис., Таллин, 1969. Я н к а уск а с Т. В. О составе акритарх ижорской свиты кембрия Русской плат-
формы. - Мат. III научной конф. геологов Литвы, Вильнюс, 1973, 6-8.

Я нкауска с Т., П ашкя вичене Л. Микропалеонтологическая характернстика юлгазеской пачки тремадока Эстонии. - Изв. АН ЭССР. Хим. Геол., 1972,
21, 92-93.

Ö pik, A. Brachiopoda Protremata der estländischen ordovizischen Kukruse-Stufe. Acta et Comm. Univ. Tartu., 1930, A XVII, 1-291.

Государственный научно-исследовательский институт горно-химического сырья (ГНГХС)

Геологическй институт Академии наук СССР
Поступила в редакцию 9/VI 1981

\section{K. HAZANOVITS, V. MISSARZEVSKI}

\section{OLGASE KIHTIDE STRATIGRAAFIAST JA HOALITELMINTIDEST EESTIS}

Korrelatsioonide põhjal naaberalade vastavate kihtidega, kust viimastel aastatel on laekunud unt paleontoloogilist materjali, on viidatud ülgase kihistiku võimalikule kuulumisele ülemkambriumi. Maardu fosforiidileiukoha puursüdamikest järeldub, et kihistik on kaheosaline. On pōhjendatud vajadust vaadelda ülgase kihistikku edaspidi kõrgemat järku ühikuna, kihistuna. On kirjeldatud kihistust leitud uut liiki Torellella sulcata.

\section{K. HAZANOVITCH, V. MISSARZHEVSKY}

\section{ON THE STRATIGRAPHY OF THE ULGASE BEDS IN ESTONIA WITH THE DESCRIPTION OF A NEW REPRESENTATIVE OF HYOLITHELMINTHES}

On the grounds of correlations with the corresponding beds of the neighbouring areas where during the recent years some new palaeontological material has come from, the

New data on the OIgase deposits made it possible to subdivide the beds into the Lower and Upper members (Fig. 1). On this basis, the Olgase Beds have been regarded
as a formation.

A new species of the genus Torellella is described from the upper member. Torellella sulcata-(Plate, Figs 2-3) differs from the other species of this genus by the presence of a longitudinal sulcus on the flank of the carapace and by a laterally con-
siderably thickened carapace wall. 